The International Archives of the Photogrammetry, Remote Sensing and Spatial Information Sciences, Volume XL-5/W3, 2013

The Role of Geomatics in Hydrogeological Risk, 27 - 28 February 2013, Padua, Italy

\title{
STRUCTURAL MONITORING WITH GEODETIC SURVEY OF QUADRIFOGLIO CONDOMINIUM (LECCE)
}

\author{
D. Costantino*, M. G. Angelini
}

Dep. DICAR, Politacnico di Bari, via Orabona, 4, 70126 Bari, Italy

(d.costantino, mg.angelini)@poliba.it

KEY WORDS: Monitoring, Risk management, Geomatic survey, Data analysis, Statistical test.

\begin{abstract}
:
Monitoring buildings for moving elements has been always a problem of great importance for their conservation and preservation, as well as for risk mitigation. In particular, topographic surveying allows, through the use of the principles and instruments of the geodetic survey, to control moving points which have been identified and measured. In this study case, twelve survey campaigns were done for monitoring a building located in the city of Lecce. The condominium was built five years ago on an old quarry filled with debris to allow construction. Later in time, obviously, cracks started to appear on walls within the property, and for this legal actions were taken. The survey schema adopted has been that of triangulation/trilateration, from two vertices with known coordinates. With this methodologies four cornerstones have been identified, established with forced centering on pillars with anchor plates, connected to same number of framework points, considered stable. From these, 23 control points located on the structure with rotating prisms anchored at the same manner have been surveyed. The elaboration has been carried out by generating redundancy of the measures and compensating the values with least mean squares. The results obtained by the activity of survey and elaboration have confirmed the existence of ongoing phenomena. The causes that have generated the phenomenon have been, subsequently, investigated and have been considered attributable to the existence of a sewer pipeline and a water pipeline not properly put in place and consequently broke down due to the geological characteristics of the site.
\end{abstract}

\section{INTRODUCTION}

The engineering structures are subjected to deformation due to - sometimes - unknown factors impacting with certain frequency and intensity (such as changes of ground water level, geotechnical phenomena, structural phenomena, etc.). Because the causes are unknown it is necessary define a conceptual model.

Monitoring and analyzing deformations of structures constitutes a special branch of Geodesy Science. The geodetic techniques allow, through a network of points interconnected by angle and distance measurements, to supply a sufficient redundancy of observations for the statistical evaluation of their quality and for error estimation. They give global information on the behaviour of the deformable structure (Moore, 1992; Glennie, 1997; Armer, 2001). Geodetic techniques have traditionally been used mainly for determining the absolute displacements of selected points on the surface of the object with respect to some reference points that are assumed to be stable. In order to establish an adequate system for monitoring, which should be non-destructive and involve long periods of time, it is necessary to take into account the environment in which such measurements are required, establish an adequate survey procedure and, finally, analyze the results obtained.

In general, the monitoring of structures has a different purpose from the testing of structural components; the dictionary definition of monitoring is to watch or listen to something carefully over a certain period of time for a special purpose (Woodhouse et al., 1999; Carpinteri, 2006; Ball, 1991).

The geodetic modelling of the object means dissecting the continuum by discrete points in such a way that the points characterize the object, and that the movements of the points represent the movements and distortions of the object. This means that only the geometry of the object is modelled. Furthermore, modelling the deformation process means conventionally to observe (by geodetic means) the characteristic points in certain time intervals in order to monitor properly the temporal course of the movements. This means that the temporal aspect of the process is modelled. This kind of modelling and monitoring of an object under deformation in space and time has been the traditional geodetic procedure. Consequently, the deformations of an object are described solely in a phenomenological manner (Welsch, 2001).

Conventionally, in order to detect possible movements, estimated coordinates obtained from least squares adjustment of observations at different epochs are compared with each other by using statistical tests. Therefore, this procedure requires a common coordinate system and the referring measurements to a common temporal fixed reference.

\subsection{Study area}

In the immediate outskirts of the city of Lecce (Apulia - Italy, figure 1) the Quadrifoglio condominium is part of a building complex which comprises of four buildings named destined to residential homes, besides a nearby villa (figure 2). The buildings of the complex are situated on a public municipal road provided in the general development plan, built together with the annexed urbanization, such as sidewalks, public lighting, water supply and drainage networks.

After about a year from the necessary permission for safety from the Municipal Technical Office, the tenants have witnessed daily signs of collapse of their homes. Due to continuous downpours, the land on which the buildings have been built have begun to lose consistency. It was, in fact, an area destined to quarry extraction of Lecce stone (figure 3), then filled with the debris material characterized by a high degree of permeability. 


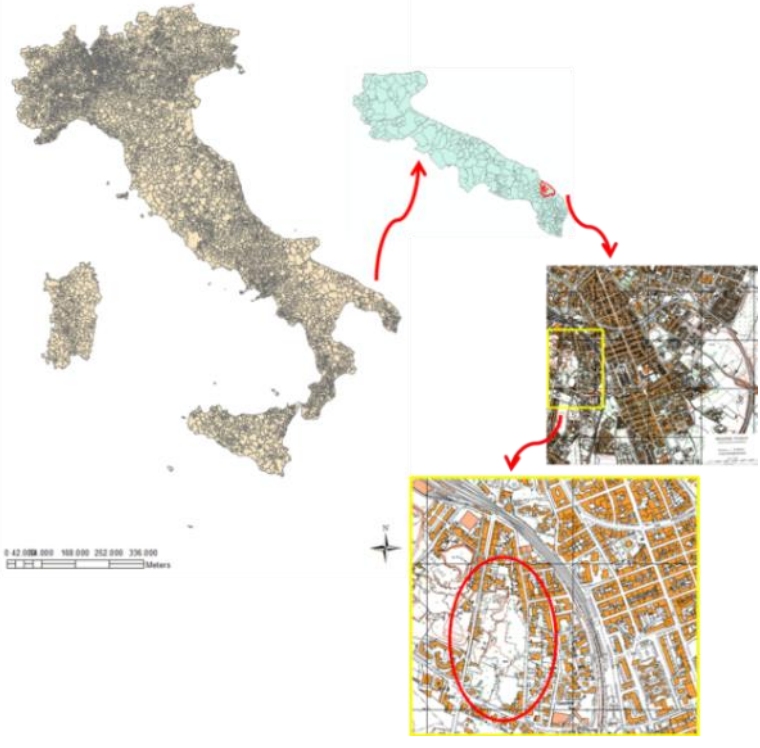

Figure 1. Study area

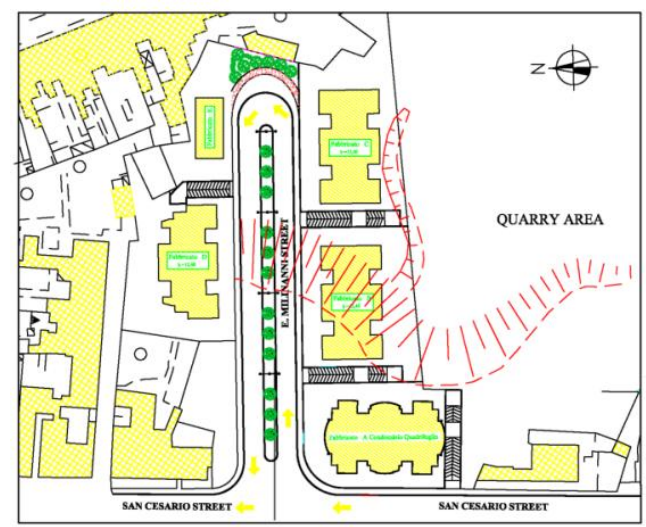

Figure 2. Building complex

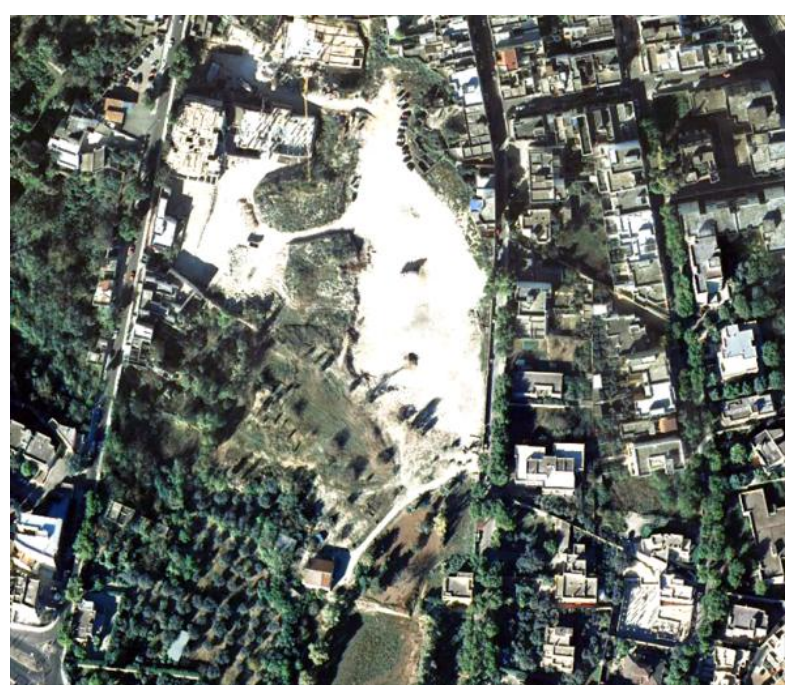

Figure 3. Quarry area before the construction
There are, however, multiple causes which have been assessed that have aggravated the situation and that call into question the failure to complete the internal road (urbanization network) and shoddy works of water and sanitation channelling.

\section{SURVEY DESIGN}

The project is divided into the following steps: (i) acquisition of general information of the structure's behaviour; (ii) identification of significant control points in order to determine the repeated readings in such a way that it has a comprehensive reading of the structural behaviour; (iii) knowledge of the characteristics of deformation and of the significant directions of movement in order to define an operating range of measurement; (iv) choice of the reference system, the operating system and the most suitable instrumentation; (v) evaluation of the minimum risk condition.

The monitoring activity has as a main reference the deformation of the structure, regardless of the quality of the materials and the size of the structure that are obviously verified and certified in the beginning. The evaluation of the risk threshold is evidently connected to the inferred values from the calculation report and the tension state that is configured with displacements greater than that of the project.

Once the maximum values not to be exceeded are fixed (risk threshold), the problem differs in the following two cases: continuous monitoring and, hence, connection of movements to units of recording that automatically trigger the alarm system or monitoring at predetermined time interval, in which the operator each time evaluates the degree of risk and behave accordingly.

\subsection{Design and installation phase}

The main question to answer was therefore if the movements of the building structure indicates a stabilization with a future decrease in risk or an active phenomena which will degenerate. A discrete monitoring was carried out using high-precision total station and forced centering for the station vertices and using fixed control points.

The geological situation previously described has required, for the installation of the cornerstones of measurement, the search of stable areas located near the structure and that respond to the need to be with each other mutually visible (Brebu, 2012).

Four stations (100, 200, 300 and 400) have been placed (figure 5), two located along San Cesario street, respectively to the right and left of the building being monitored, one located on the roof of a building place to North-West of the building and finally, the fourth positioned in construction area located SouthWest of the building.

The reference system adopted for the control activities corresponding to the cornerstones is shown in figure 6 , and is a local reference system with origin at the vertex $100, \mathrm{x}$-axis along the line joining the vertex 100 with 400 and axis y such as to complete the clockwise triad. 


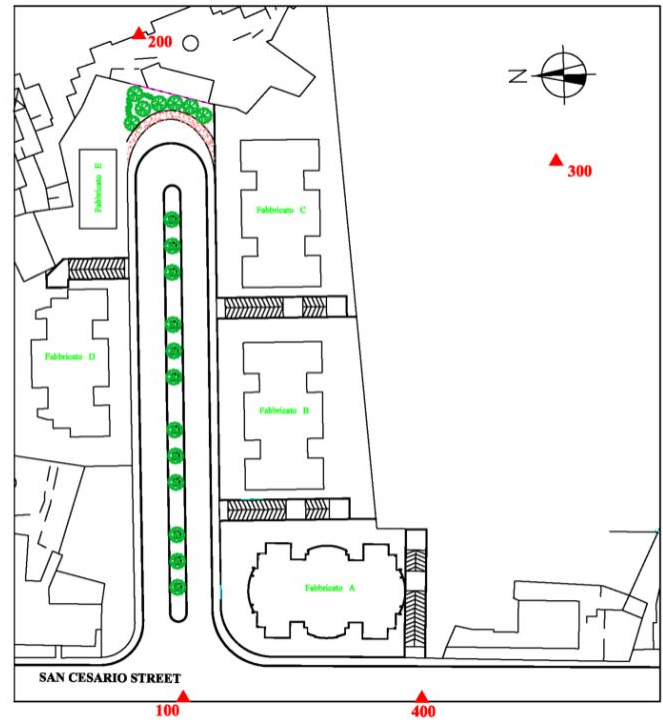

Figure 5. Scheme of the cornerstones of the network

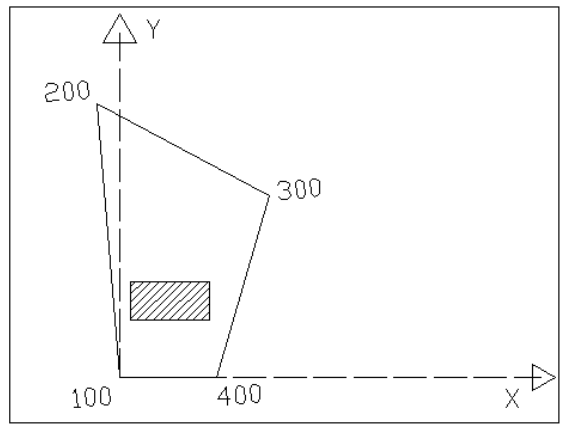

Figure 6. Scheme of survey

For each cornerstone a structure was built consisting of a a square base 100x100x20 cm on which has been built a pillar of square cross-section $40 \times 40 \times 160 \mathrm{~cm}$

The points to be checked, in the design phase, have been chosen in function of their visibility from at least two stations and, in any case, structurally significant.

On each of them has been planned the installation of a forced centering consisting of a pivot port prism for tunnels and artifacts and a miniprism with metal frames, complete with spirit level, target plate, centering accuracy of $1 \mathrm{~mm}$ and a reflective range of $2000 \mathrm{~m}$.

\section{TOPOGRAPHIC NETWORK}

Each of the four stations have been connected to two other external vertices, as it is necessary to double check if the network is robust. From these stations the final network which was realized connected each to the 23 control vertices placed on the building (figures 7-9). The redundancy of the scheme of the network has allowed a good control of the error propagation and of the presence of any gross errors, and the further rigorous compensation of vertices with the estimate of the coordinates and of the precision corresponding (Deakin, 1999).

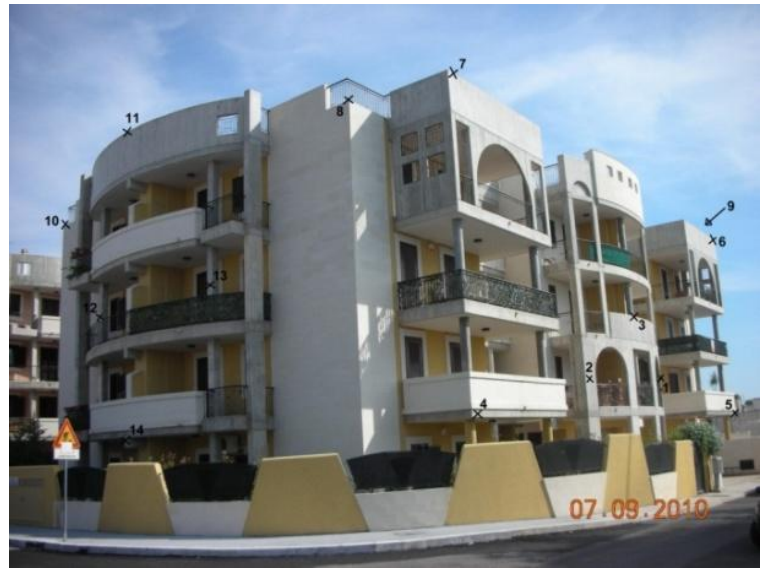

Figure 7. Control vertices located on the North and West sides

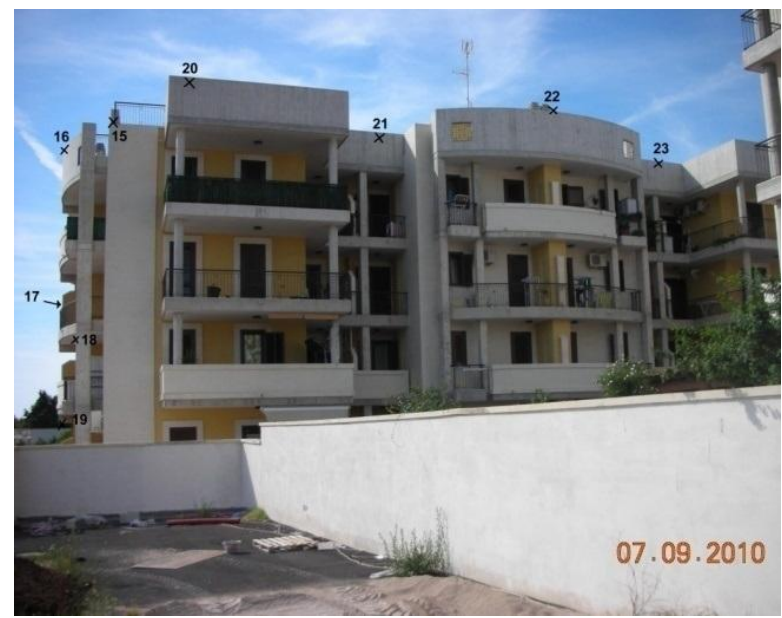

Figure 8. Control vertices located on the East side

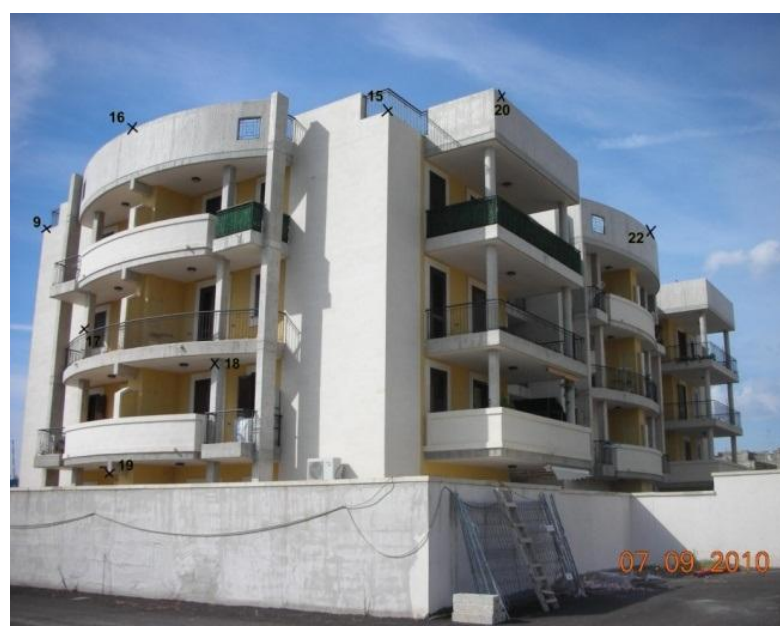

Figure 9. Control vertices located on the South and East sides

The compensation has been performed with the least squares method using the equations of observation that bind the measurements performed with the parameters to be estimated (the coordinates of the vertices). The planimetric problem has been split out from the one altimetric by performing, respectively, a compensation to the angles and distances and one to the heights (Henriques, 2001). 
The method implemented the compensation with the method of least squares with variable number of iterations (maximum 10), until the stabilization of the estimated RMS (Root Mean Square).

For vertices without redundancy, in the absence of constraints the coordinates have been calculated without an estimation of the errors (Sepe, 2007).

Topographically the network has been realized by executing the schema of triangulation (figure 10) in which, starting from two cornerstones, the control vertices $P i\left(x_{i}, y_{i}\right)$ have been measured.

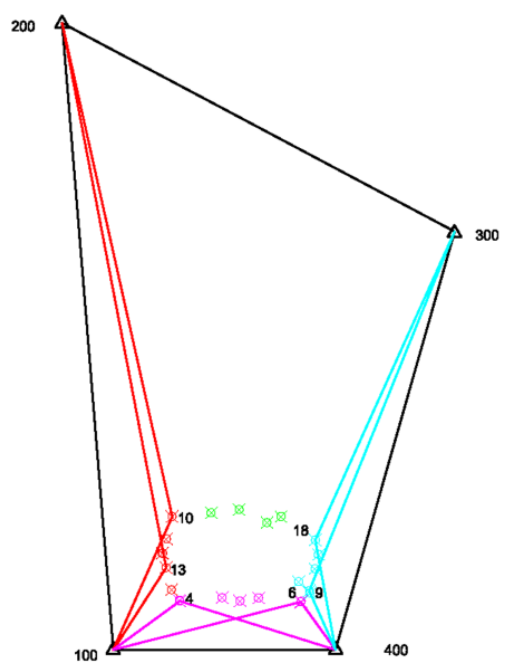

Figure 10. Triangulation schema

For each control vertex its ellipse error has been calculated using the matrix of variance-covariance of the planimetric coordinates $(\mathrm{x}, \mathrm{y})$.

The surveys have been performed in the following dates: 05/11/2010, 22/11/2010, 06/12/2010, 20/12/2010, 07/01/2011, 20/01/2011, 04/02/2011, 25/02/2011, 15/03/2011, 31/03/2011, 09/05/2011,25/05/2011, using a TS30 Leica Geosystems total station.

The system enables angular measurements of great accuracy and reliability and is, moreover, equipped with a dual-axis compensator that constantly monitors both components of the inclination of the vertical axis (Dunisch, 2001).

In table 1 the accuracy specifications of the instrument used are shown.

\begin{tabular}{|l|}
\hline Accuracy std. Dev. ISO 17123-3 \\
\hline Hz, V: 0.5 "(0.15 mgon) \\
\hline $\begin{array}{l}\text { Accuracy std. Dev. ISO 17123-4/Measure } \\
\text { time }\end{array}$ \\
\hline Precise mode: $0.6 \mathrm{~mm}+1 \mathrm{ppm} / \mathrm{typ} .7 \mathrm{~s}$ \\
\hline
\end{tabular}

Table 1. Accuracy TS30

The coordinates of the stations 100, 200, 300 and 400 have been calculated and re-determined as shown in table 2.

\begin{tabular}{|c|c|c|c|}
\hline Stations & $\mathbf{X}[\mathbf{m}]$ & $\mathbf{Y}[\mathbf{m}]$ & Quote $[\mathbf{m}]$ \\
\hline 100 & 0.0000 & 0.0000 & 1.500 \\
\hline 400 & 54.2119 & 0.0000 & 11.353 \\
\hline 300 & 83.1529 & 101.4927 & 1.134 \\
\hline 200 & -12.4714 & 152.4675 & 0.628 \\
\hline
\end{tabular}

Table 2. Coordinates of the station vertices

For each day of survey the stability of the same has been evaluated and it has been verified that any errors were contained in the precision of the method and that they were less than the measured displacements of the control vertices (table 3 ).

\begin{tabular}{|c|c|c|c|c|c|c|}
\hline \multirow[b]{2}{*}{ ID } & \multicolumn{3}{|c|}{ 05-11-10/22-11-10 } & \multicolumn{3}{|c|}{$05-11-10 / 25-05-11$} \\
\hline & $\begin{array}{l}\Delta \mathbf{X} \\
{[\mathbf{m}]}\end{array}$ & $\begin{array}{l}\Delta \mathbf{Y} \\
{[\mathbf{m}]}\end{array}$ & $\begin{array}{l}\Delta \mathbf{Q} \\
{[\mathrm{m}]}\end{array}$ & $\begin{array}{l}\Delta \mathbf{X} \\
{[\mathbf{m}]}\end{array}$ & $\begin{array}{l}\Delta \mathbf{Y} \\
{[\mathbf{m}]}\end{array}$ & $\begin{array}{l}\Delta \mathbf{Q} \\
{[\mathrm{m}]}\end{array}$ \\
\hline $\begin{array}{c}10 \\
0\end{array}$ & $\begin{array}{c}0.000 \\
0\end{array}$ & $\begin{array}{c}0.000 \\
1\end{array}$ & 0.000 & 0.0000 & 0.0000 & 0.000 \\
\hline $\begin{array}{c}40 \\
0\end{array}$ & $\begin{array}{c}0.000 \\
2\end{array}$ & $\begin{array}{c}0.000 \\
0\end{array}$ & 0.002 & 0.0001 & 0.0000 & 0.001 \\
\hline $\begin{array}{c}30 \\
0 \\
\end{array}$ & $\begin{array}{c}0.000 \\
0 \\
\end{array}$ & $\begin{array}{c}0.000 \\
1 \\
\end{array}$ & -0.001 & 0.0001 & 0.0001 & 0.001 \\
\hline $\begin{array}{c}20 \\
0\end{array}$ & $\begin{array}{c}- \\
0.000 \\
3\end{array}$ & $\begin{array}{c}- \\
0.000 \\
2\end{array}$ & -0.001 & 0.0002 & $\begin{array}{c}- \\
0.0001\end{array}$ & 0.000 \\
\hline
\end{tabular}

Table 3. Verification the stability of station vertices

Starting from these vertices the control points of the network have been compensated both planimetrically and altimetrically. In particular, in table 5 the control points not visible by two vertices of station are shown in yellow.

Subsequently, the results have been compared of the different campaigns with those of the survey zero ( $\mathrm{t} 0$ corresponds to 5/11/2012) (table 4).

For each control vertex the values of the variances and the covariances of the three coordinates have been determined (table 5) and, consequently, the parameters related to the error ellipses have been calculated.

\begin{tabular}{|c|c|c|c|c|c|c|c|c|c|}
\hline \multirow{2}{*}{ ID } & \multicolumn{3}{|c|}{ 05_11_10/20_12_10 } & \multicolumn{3}{|c|}{ 05_11_10/25_02_11 } & \multicolumn{3}{|c|}{ 05_11_10/25_05_11 } \\
\hline & $\Delta \mathrm{X}[\mathrm{m}]$ & $\Delta \mathrm{Y}[\mathrm{m}]$ & $\Delta \mathrm{Q}[\mathrm{m}]$ & $\Delta \mathrm{X}[\mathrm{m}]$ & $\Delta \mathrm{Y}[\mathrm{m}]$ & $\Delta \mathrm{Q}[\mathrm{m}]$ & $\Delta \mathrm{X}[\mathrm{m}]$ & $\Delta \mathrm{Y}[\mathrm{m}]$ & $\Delta \mathrm{Q}[\mathrm{m}]$ \\
\hline 1 & 0.000 & -0.001 & 0.010 & 0.000 & -0.001 & 0.013 & 0.000 & -0.001 & 0.015 \\
\hline 2 & 0.000 & -0.001 & 0.007 & -0.001 & -0.002 & 0.008 & 0.000 & -0.001 & 0.010 \\
\hline 3 & -0.001 & -0.001 & 0.008 & -0.001 & -0.002 & 0.009 & -0.001 & -0.002 & 0.011 \\
\hline 4 & 0.000 & -0.001 & 0.005 & -0.001 & -0.001 & 0.006 & -0.001 & -0.001 & 0.007 \\
\hline 5 & 0.000 & 0.000 & 0.011 & 0.000 & 0.000 & 0.012 & 0.000 & 0.000 & 0.015 \\
\hline 6 & 0.000 & 0.000 & 0.010 & 0.001 & 0.001 & 0.006 & 0.001 & 0.001 & 0.007 \\
\hline 7 & 0.000 & 0.000 & 0.007 & -0.001 & -0.003 & 0.009 & -0.001 & -0.002 & 0.011 \\
\hline 8 & 0.000 & 0.000 & 0.011 & 0.000 & 0.000 & 0.030 & 0.001 & 0.001 & 0.035 \\
\hline 9 & 0.003 & -0.004 & 0.015 & 0.011 & -0.011 & 0.016 & 0.010 & -0.012 & 0.020 \\
\hline 10 & -0.001 & 0.005 & -0.002 & -0.006 & 0.009 & -0.003 & -0.009 & 0.017 & -0.003 \\
\hline 11 & -0.001 & 0.003 & -0.002 & -0.004 & 0.010 & -0.002 & -0.006 & 0.015 & -0.002 \\
\hline 12 & 0.000 & 0.002 & -0.002 & -0.001 & 0.006 & -0.002 & -0.003 & 0.011 & -0.003 \\
\hline 13 & 0.000 & 0.005 & -0.002 & -0.002 & 0.011 & -0.002 & -0.002 & 0.013 & -0.002 \\
\hline 14 & 0.001 & 0.002 & -0.002 & -0.002 & 0.005 & -0.002 & 0.001 & 0.009 & -0.002 \\
\hline 15 & 0.006 & -0.002 & 0.009 & 0.012 & -0.008 & 0.014 & 0.014 & -0.013 & 0.013 \\
\hline 16 & -0.003 & 0.002 & 0.008 & 0.003 & -0.005 & 0.009 & 0.003 & -0.009 & 0.008 \\
\hline 17 & 0.009 & -0.002 & 0.015 & 0.008 & -0.009 & 0.016 & 0.009 & -0.010 & 0.020 \\
\hline 18 & 0.001 & \begin{tabular}{|c|}
-0.003 \\
\end{tabular} & 0.014 & 0.009 & $\begin{array}{l}-0.008 \\
\end{array}$ & 0.015 & 0.009 & -0.010 & 0.020 \\
\hline 19 & 0.002 & -0.002 & 0.015 & 0.005 & -0.006 & 0.015 & 0.005 & -0.008 & 0.020 \\
\hline 20 & 0.008 & -0.002 & 0.009 & 0.013 & -0.009 & 0.015 & 0.016 & -0.014 & 0.018 \\
\hline 21 & 0.006 & -0.002 & 0.011 & 0.010 & -0.007 & 0.019 & 0.013 & -0.013 & 0.018 \\
\hline 22 & 0.005 & -0.002 & 0.012 & 0.011 & -0.006 & 0.024 & 0.013 & -0.013 & 0.026 \\
\hline 23 & 0.007 & -0.002 & 0.012 & 0.012 & -0.008 & 0.025 & 0.015 & -0.012 & 0.028 \\
\hline
\end{tabular}

Table 4. Comparison of the vertices coordinates with time $t_{0}$ 
The International Archives of the Photogrammetry, Remote Sensing and Spatial Information Sciences, Volume XL-5/W3, 2013 The Role of Geomatics in Hydrogeological Risk, 27 - 28 February 2013, Padua, Italy

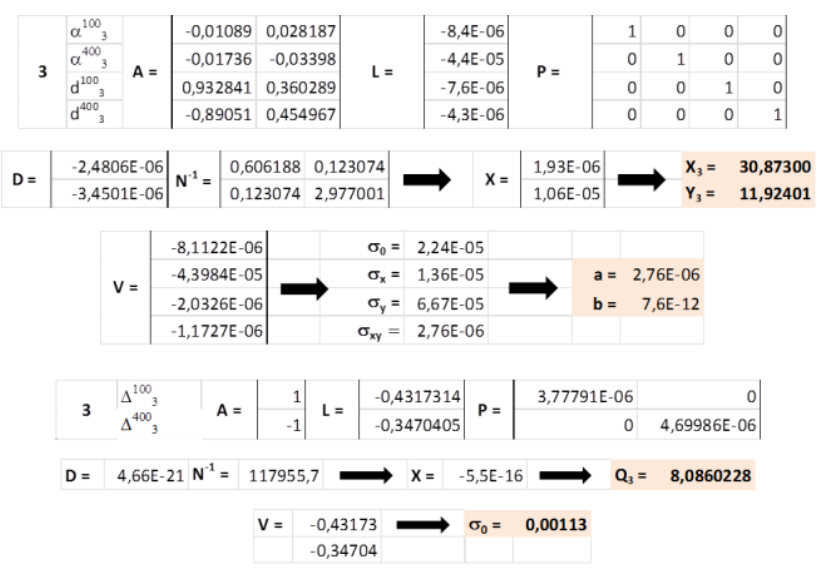

Table 5. Example of calculation

\section{STATISTICAL TESTING}

In monitoring the object to be investigated is typically represented by a cluster of points, whose positions are fixed by topographic measures at different epochs of time. If movements occur, they cause displacements of the cluster, resulting in position differences between epochs. These differences can be, typically, of the same order of magnitude as the observational errors. Therefore, statistical analyses and particularly hypothesis testing are needed to reasonably detect significant displacement of individual control points or significant network deformations. For example, the global congruency test (Cooper, 1987; Setan, 1995; Erol, 2004; Barbarella, 1990) may be a useful tool for the examination of the total deformation of a network between two epochs. If the observed deformation is small compared to the accuracy of the measurements, the network is regarded as congruent at those two epochs, otherwise the observed deformation is deemed significant, which usually requires further analyses.

Two statistical approaches have been applied in this case: the classical statistical approach and the Bayesian approach.

The classical statistic considers the data as realizations of random variables and the unknown parameters as deterministic, while in Bayesian statistics the data are considered constant and the unknown parameters are random variables characterized by a priori $\operatorname{pdf} P(\theta)$.

Therefore, the Bayesian approach allows one to refresh a priori information contained in the $\operatorname{pdf} P(\theta)$ of the parameters, given the data produced, and the update is reflected in the definition of a $\operatorname{pdf} P(\theta \mid d)$ a posteriori.

\subsection{Test of classical statistics}

In a first hypothesis it is assumed that the adjusted observations collected in the first survey are uncorrelated, both in the spatial domain (distance between points) and in the time domain (time between measurement sessions), with respect to those acquired in the subsequent phases.

It is also assumed that estimated point coordinates in the repeated surveys

$\left(\mathrm{x}_{0}=\mathrm{x}\left(\mathrm{t}_{0}\right), \mathrm{x}_{\mathrm{i}}=\mathrm{x}\left(\mathrm{t}_{\mathrm{i}}\right)\right)$

and their differences $\Delta x=x_{i}-x_{0}$ are normally distributed, with variance respectively $\left(\sigma_{x 0}^{2}, \sigma_{x i}^{2}\right)$ and $\left(\sigma_{x 0}^{2}+\sigma_{x i}^{2}\right)$.

With such assumptions it turns that:

$$
\Delta x \in \mathrm{N}\left(\delta \mathrm{x} ; \sigma_{x 0}{ }^{2}+\sigma_{x i}{ }^{2}\right)
$$

where:

$\delta_{x}$ is unknown,

$\left(\sigma_{x 0}^{2}, \sigma_{x i}^{2}\right)$ are known from the least squares adjustment of the observations.

The null and alternative hypothesis for congruency testing are

$H_{0}: \delta x=0$

(i.e no significant deformation occurred for a point between two epochs)

$H_{1}: \delta x \neq 0$

(i.e existence of significant deformation)with the following test statistics:

$$
Z=\frac{\Delta x}{\sqrt{\left(\sigma_{x 0}^{2}+\sigma_{x i}^{2}\right)}}
$$

The null hypothesis is, therefore, accepted at the $\square \square$ level of significance if the test statistic (3) does not exceed the critical value of the $\mathrm{Z}$ distribution (normal standardized distribution). In this study a significance level of $\mathrm{p}=5 \%$ has been applied, which gave a $Z_{\text {crit }}=1.96$ (Baarda, 1968).

In order to better discriminate if the differences in point positions were due to actual displacements or to random errors and/or movements of the control points, the test has been applied as in table 6 and 7 (Costantino, 2011). The points that showing statistically relevant displacements are highlighted in

\begin{tabular}{|c|c|c|c|c|c|c|}
\hline \multirow{2}{*}{ ID } & \multicolumn{6}{|c|}{ 05_11_10/25_02_11 } \\
\hline & $\Delta \mathrm{x}$ & $\Delta \mathrm{Y}$ & $\Delta \mathbf{Q}$ & $\mathbf{Z}_{\alpha / 2} \mathbf{X}$ & $\mathrm{Z}_{\alpha / 2} \mathrm{Y}$ & $Z_{\alpha / 2} Q$ \\
\hline 1 & 0.0005 & -0.0013 & 0.013 & 16.10125 & -12.13783 & 7.83272 \\
\hline 2 & -0.0010 & -0.0020 & 0.008 & -46.24311 & -20.52014 & 4.21598 \\
\hline 3 & -0.0010 & -0.0020 & 0.009 & -22.66705 & -9.18687 & 5.70928 \\
\hline 4 & -0.0010 & -0.0010 & 0.006 & -40.54270 & -11.35284 & 2.85926 \\
\hline 5 & 0.0000 & 0.0000 & 0.012 & -0.11643 & -0.08580 & 6.68820 \\
\hline 6 & 0.0010 & 0.0010 & 0.006 & 19.52362 & 11.11053 & 3.06884 \\
\hline 7 & -0.0010 & -0.0030 & 0.009 & -12.97795 & -11.31844 & 3.99006 \\
\hline 8 & 0.0001 & 0.0001 & 0.030 & - & - & - \\
\hline 9 & 0.0109 & -0.0106 & 0.016 & 1.84952 & -10.50286 & 14.38631 \\
\hline 10 & -0.0063 & 0.0092 & 0.003 & -3.79927 & 46.78524 & 1.50273 \\
\hline 11 & -0.0045 & 0.0098 & 0.002 & -6.02280 & 95.18256 & 1.88651 \\
\hline 12 & -0.0013 & 0.0064 & 0.002 & -3.15851 & 118.93912 & 3.61124 \\
\hline 13 & -0.0023 & 0.0108 & 0.002 & -3.97573 & 97.17732 & 1.97321 \\
\hline 14 & -0.0023 & 0.0052 & 0.002 & -4.15835 & 68.07091 & 4.08060 \\
\hline 15 & 0.0124 & -0.0078 & 0.014 & - & 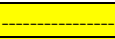 & - \\
\hline 16 & 0.0030 & -0.0046 & 0.009 & & & \\
\hline 17 & 0.0085 & -0.0094 & 0.016 & 11.38116 & -106.54616 & 51.20044 \\
\hline 18 & 0.0090 & -0.0082 & 0.015 & 26.91256 & -214.72485 & 141.23541 \\
\hline 19 & 0.0045 & -0.0065 & 0.015 & 7.85332 & -107.52395 & 94.04811 \\
\hline 20 & 0.0131 & -0.0087 & 0.015 & & - & - \\
\hline 21 & 0.0100 & -0.0073 & 0.019 & & 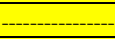 & \\
\hline 22 & 0.0106 & -0.0065 & 0.024 & & & \\
\hline 23 & 0.0124 & -0.0076 & 0.025 & & & \\
\hline
\end{tabular}
bold.

Table 6. Differences of adjusted coordinates and statistical analysis results between the survey of 05/11/2010 and 25/02/2011. 
The International Archives of the Photogrammetry, Remote Sensing and Spatial Information Sciences, Volume XL-5/W3, 2013 The Role of Geomatics in Hydrogeological Risk, 27 - 28 February 2013, Padua, Italy

\begin{tabular}{|c|c|c|c|c|c|c|}
\hline \multirow{2}{*}{ ID } & \multicolumn{6}{|c|}{ 05_11_10/25_05_11 } \\
\hline & $\Delta \mathbf{x}$ & $\Delta \mathrm{Y}$ & $\Delta \mathrm{Q}$ & $\mathrm{Z}_{\alpha / 2} \mathrm{X}$ & $Z_{\alpha / 2} Y$ & $\mathbf{Z}_{\alpha / 2} \mathbf{Q}$ \\
\hline 1 & 0.0005 & -0.0013 & 0.013 & 16.10125 & -12.13783 & 7.83272 \\
\hline 2 & -0.0010 & -0.0020 & 0.008 & -46.24311 & -20.52014 & 4.21598 \\
\hline 3 & -0.0010 & -0.0020 & 0.009 & -22.66705 & -9.18687 & 5.70928 \\
\hline 4 & -0.0010 & -0.0010 & 0.006 & -40.54270 & -11.35284 & 2.85926 \\
\hline 5 & 0.0000 & 0.0000 & 0.012 & -0.11643 & -0.08580 & 6.68820 \\
\hline 6 & 0.0010 & 0.0010 & 0.006 & 19.52362 & 11.11053 & 3.06884 \\
\hline 7 & -0.0010 & -0.0030 & 0.009 & -12.97795 & -11.31844 & 3.99006 \\
\hline 8 & 0.0001 & 0.0001 & 0.030 & & & \\
\hline 9 & 0.0109 & -0.0106 & 0.016 & 1.84952 & -10.50286 & 14.38631 \\
\hline 10 & -0.0063 & 0.0092 & 0.003 & -3.79927 & 46.78524 & 1.50273 \\
\hline 11 & -0.0045 & 0.0098 & 0.002 & -6.02280 & 95.18256 & 1.88651 \\
\hline 12 & -0.0013 & 0.0064 & 0.002 & -3.15851 & 118.93912 & 3.61124 \\
\hline 13 & -0.0023 & 0.0108 & 0.002 & -3.97573 & 97.17732 & 1.97321 \\
\hline 14 & -0.0023 & 0.0052 & 0.002 & -4.15835 & 68.07091 & 4.08060 \\
\hline 15 & 0.0124 & -0.0078 & 0.014 & & & \\
\hline 16 & 0.0030 & -0.0046 & 0.009 & - & - & - \\
\hline 17 & 0.0085 & -0.0094 & 0.016 & 11.38116 & -106.54616 & 51.20044 \\
\hline 18 & 0.0090 & -0.0082 & 0.015 & 26.91256 & -214.72485 & 141.23541 \\
\hline 19 & 0.0045 & -0.0065 & 0.015 & 7.85332 & -107.52395 & 94.04811 \\
\hline 20 & 0.0131 & -0.0087 & 0.015 & & & \\
\hline 21 & 0.0100 & -0.0073 & 0.019 & & & \\
\hline 22 & 0.0106 & -0.0065 & 0.024 & & & \\
\hline 23 & 0.0124 & -0.0076 & 0.025 & & & \\
\hline
\end{tabular}

Table 7. Differences of adjusted coordinates and statistical analysis results between the first and the last survey.

\subsection{Bayesian analysis of the displacements of the network}

For the application of Bayesian analysis it has been decided to adopt a simplified approach, analyzing separately the three coordinates and, therefore, considering it one-dimensional. It is considered, therefore, the single coordinate, called $h$, obtained by compensation of the network at different times.

The quantities to be considered are the displacements $\Delta h$ between the different sessions ( $i$ ) of all control points of the network $\mathrm{P}_{\mathrm{j}}$ :

$(\Delta h)_{P_{j}}=\left(h_{i}-h_{0}\right)_{P_{j}}$

with $\quad \mathrm{i}=1,2, \ldots, 11$

$$
\mathrm{j}=1,2, \ldots, 23 \text {. }
$$

$\Delta h$ follows a normal distribution with mean $\delta h$ (unknown) and variance $\sigma_{h}^{2}$ (known from previous compensation).

Therefore, for each point of the network it can be written:

$\Delta h=h_{i}-h_{0}=\delta h+\sigma_{h}$.

The average $\delta h$ is, in turn, a random variable that we suppose is distributed with a normal probability density, with average $\mu$ and variance $\sigma_{0}^{2}$. The parameters of this distribution, defined as the prior of the Bayesian formulation, are the a prior information $\left(\mu, \sigma_{0}^{2}\right)$ will be fixed during the numerical treatment of the problem.

Starting from the Bayes formula:

$f(\delta h \mid \Delta h)=\frac{f(\Delta h \mid \delta h) \cdot f(\delta h)}{\int_{-\infty}^{+\infty} f(\Delta h \mid \delta h) \cdot f(\delta h) \cdot d(\delta h)}$

It is possible to clarify the terms of the second member, first considering the normal distribution and, subsequently, assuming that if there are no displacements $(\delta h=0)$, this which corresponds to $P_{0} \equiv P\{\delta h=0\}$.
The function prior, probability distribution of the parameter $\delta h$, with this constraint is:

$f(\delta h)=P_{0} \delta(\delta h)+\frac{\vartheta(\delta h)}{\sigma_{0} \sqrt{2 \pi}} \cdot e^{-(\delta h-\mu)^{2}} / 2 \sigma_{0}^{2}$

where:

$\vartheta(\delta h)=1$ for $\delta h \neq 0$

$\vartheta(\delta h)=0$ for $\delta h=0$

$\delta(\delta h)=$ delta function ofDirac.

From these, the final formulation can be reached, summarized below:

$P(\delta h \neq 0 \mid \Delta h)=\int_{0}^{+\infty} P(\delta h \mid \Delta h) \cdot d(\delta h)=\frac{B}{A+B}$

and

$P(\delta h=0 \mid \Delta h)=\frac{1}{A+B} \cdot \frac{P_{0}}{\sqrt{2 \pi} \cdot \sigma_{h}} \cdot e^{-\frac{\Delta h^{2}}{2 \sigma_{h}^{2}}}=\frac{A}{A+B}$

with:

$P_{0}=\operatorname{erf}\left(-\frac{\mu}{\sigma_{0}}\right)$

$A \equiv \frac{P_{0}}{\sqrt{2 \pi} \cdot \sigma_{h}} \cdot e^{-\Delta h^{2} / 2} \sigma_{h}^{2}$

and

$B \equiv \frac{\bar{\sigma} \cdot e^{\frac{\left(h_{i} \cdot \Delta h^{2}+h_{0} \cdot \mu^{2}-\bar{h} \cdot m^{2}\right)}{2}}}{\sqrt{2 \pi} \cdot \sigma_{h} \cdot \sigma_{0}}\left[1-\operatorname{erf}\left(-\frac{m}{\bar{\sigma}}\right)\right]$

where:

$\bar{\sigma}=$ mean of the variances between $\mathrm{t}_{\mathrm{i}}$ epochs and $\sigma_{0}$;

$m=$ mean of the displacements in the two epochs;

$\bar{h}=$ mean value of the coordinate in the two epochs; erf $=$ error function (Beyer, 1978).

The significance analysis of movements by the Bayesian approach will make possible, therefore, a reduction to a comparison between the two equations of (8).

The interpretation of the results Bayesian analysis has been carried out recalling that in planimetry the expected accuracies are on the order of tenths of a millimeter, while in altimetry of millimeter, with a significance level $\alpha=5 \%$.

On the basis of these considerations, six different elaborations have been made, depending on the initial assumptions.

The values of $P(\delta h \neq 0)$ resulting from the comparison of all the survey measurements with the first, are reported below with reference to the first, the third and the sixth elaboration. 
The International Archives of the Photogrammetry, Remote Sensing and Spatial Information Sciences, Volume XL-5/W3, 2013 The Role of Geomatics in Hydrogeological Risk, 27 - 28 February 2013, Padua, Italy

\begin{tabular}{|c|r|r|r|}
\hline \multirow{2}{*}{ ID } & \multicolumn{3}{|c|}{$\mathbf{0 5 / 1 1 / 2 0 1 0 - 2 5 / 0 2 / 2 0 1 1}$} \\
\cline { 2 - 4 } & $\mathbf{P}(\boldsymbol{\delta} \mathbf{h} \neq \mathbf{0}) \mathbf{( X )}$ & $\mathbf{P}(\boldsymbol{\delta} \mathbf{h} \mathbf{0}) \mathbf{( Y )}$ & $\mathbf{P}(\boldsymbol{\delta} \mathbf{h} \neq \mathbf{0})(\mathbf{Q})$ \\
\hline 1 & 1.000 & 1.000 & 1.000 \\
\hline 2 & 1.000 & 1.000 & 1.000 \\
\hline 3 & 1.000 & 1.000 & 1.000 \\
\hline 4 & 1.000 & 1.000 & 0.999 \\
\hline 5 & 0.142 & 0.140 & 1.000 \\
\hline 6 & 1.000 & 1.000 & 1.000 \\
\hline 7 & 1.000 & 1.000 & 1.000 \\
\hline 8 & & & \\
\hline 9 & 0.785 & 1.000 & 1.000 \\
\hline 10 & 0.978 & 1.000 & 0.835 \\
\hline 11 & 1.000 & 1.000 & 0.934 \\
\hline 12 & 0.956 & 1.000 & 1.000 \\
\hline 13 & 0.996 & 1.000 & 0.943 \\
\hline 14 & 0.999 & 1.000 & 1.000 \\
\hline 15 & & & \\
\hline 16 & & & \\
\hline 17 & 1.000 & 1.000 & 1.000 \\
\hline 18 & 1.000 & 1.000 & 1.000 \\
\hline 19 & 1.000 & 1.000 & 1.000 \\
\hline 20 & & & \\
\hline 21 & & & \\
\hline 22 & & & \\
\hline 23 & & & \\
\hline & & & \\
\hline
\end{tabular}

Table 10. Results of Bayesian analysis with prior data $\mu=0.005$ $\mathrm{m}$ and $\sigma_{0}=0.006 \mathrm{~m}$

\begin{tabular}{|c|r|r|r|}
\hline \multirow{2}{*}{ ID } & \multicolumn{3}{|c|}{$\mathbf{0 5 / 1 1 / 2 0 1 0 - 2 5 / 0 2 / 2 0 1 1}$} \\
\cline { 2 - 4 } & $\mathbf{P}(\boldsymbol{\delta} \mathbf{h} \neq \mathbf{0}) \mathbf{( X )}$ & $\mathbf{P}(\boldsymbol{\delta} \mathbf{h} \neq \mathbf{0})(\mathbf{Y})$ & $\mathbf{P}(\boldsymbol{\delta} \mathbf{h} \neq \mathbf{0})(\mathbf{Q})$ \\
\hline 1 & 1.000 & 1.000 & 1.000 \\
\hline 2 & 1.000 & 1.000 & 1.000 \\
\hline 3 & 1.000 & 1.000 & 1.000 \\
\hline 4 & 1.000 & 1.000 & 0.999 \\
\hline 5 & 0.042 & 0.041 & 1.000 \\
\hline 6 & 1.000 & 1.000 & 1.000 \\
\hline 7 & 1.000 & 1.000 & 1.000 \\
\hline 8 & & & \\
\hline 9 & 0.811 & 1.000 & 1.000 \\
\hline 10 & 0.918 & 1.000 & 0.696 \\
\hline 11 & 1.000 & 1.000 & 0.850 \\
\hline 12 & 0.848 & 1.000 & 1.000 \\
\hline 13 & 0.984 & 1.000 & 0.863 \\
\hline 14 & 0.995 & 1.000 & 1.000 \\
\hline 15 & & & \\
\hline 16 & & & \\
\hline 17 & 1.000 & 1.000 & 1.000 \\
\hline 18 & 1.000 & 1.000 & 1.000 \\
\hline 19 & 1.000 & 1.000 & 1.000 \\
\hline 20 & & & \\
\hline 21 & & & \\
\hline 22 & & & \\
\hline 23 & & & \\
\hline & & & \\
\hline
\end{tabular}

Table 11. Results of Bayesian analysis with prior data $\mu=$ $0.0075 \mathrm{~m}$ and $\sigma_{0}=0.006 \mathrm{~m}$

In tables $10,11,12,13$ the results of the test are reported. In particular, in table 12 the first elaboration between the survey of $05 / 11 / 2010$ and 25/02/2011 with prior data $\mu=0.005 \mathrm{~m}$ and $\sigma_{0}=0.006 \mathrm{~m}$, are reported.

In table 11 the third elaboration for the same date and prior data $\mu=0.0075 \mathrm{~m}$ and $\sigma_{0}=0.006 \mathrm{~m}$ are reported.

In table 12 the sixth elaboration for the same date and prior data $\mu=0.01 \mathrm{~m}$ and $\sigma_{0}=0.006 \mathrm{~m}$ are reported.

Finally, table 12 show the result of the sixth elaboration between the survey of 05/11/2010 and 25/05/2011 with prior data $\mu=0.01 \mathrm{~m}$ and $\sigma_{0}=0.006 \mathrm{~m}$.

\begin{tabular}{|c|r|r|r|}
\hline \multirow{2}{*}{ ID } & \multicolumn{3}{|c|}{$\mathbf{0 5 / 1 1 / 2 0 1 0 - 2 5 / 0 2 / 2 0 1 1}$} \\
\cline { 2 - 4 } & $\mathbf{P}(\boldsymbol{\delta} \mathbf{h} \neq \mathbf{0}) \mathbf{( X )}$ & $\mathbf{P}(\boldsymbol{\delta} \mathbf{h} \neq \mathbf{0})(\mathbf{Y})$ & $\mathbf{P}(\boldsymbol{\delta} \mathbf{h} \neq \mathbf{0})(\mathbf{Q})$ \\
\hline 1 & 1.000 & 1.000 & 1.000 \\
\hline 2 & 1.000 & 1.000 & 1.000 \\
\hline 3 & 1.000 & 1.000 & 1.000 \\
\hline 4 & 1.000 & 1.000 & 0.998 \\
\hline 5 & 0.010 & 0.010 & 1.000 \\
\hline 6 & 1.000 & 1.000 & 1.000 \\
\hline 7 & 1.000 & 1.000 & 1.000 \\
\hline 8 & & & \\
\hline 9 & 0.843 & 1.000 & 1.000 \\
\hline 10 & 0.715 & 1.000 & 0.497 \\
\hline 11 & 1.000 & 1.000 & 0.681 \\
\hline 12 & 0.559 & 1.000 & 1.000 \\
\hline 13 & 0.927 & 1.000 & 0.688 \\
\hline 14 & 0.979 & 1.000 & 1.000 \\
\hline 15 & & & \\
\hline 16 & & & \\
\hline 17 & 1.000 & 1.000 & 1.000 \\
\hline 18 & 1.000 & 1.000 & 1.000 \\
\hline 19 & 1.000 & 1.000 & 1.000 \\
\hline 20 & & & \\
\hline 21 & & & \\
\hline 22 & & & \\
\hline 23 & & & \\
\hline & & & \\
\hline
\end{tabular}

Table 12. Results of Bayesian analysis with prior data $\mu=0.01$ $\mathrm{m}$ and $\sigma_{0}=0.006 \mathrm{~m}$

\begin{tabular}{|c|r|r|r|}
\hline \multirow{2}{*}{ ID } & \multicolumn{3}{|c|}{$\mathbf{5 / 1 1 / 2 0 1 0 - 2 5 / 0 5 / 2 0 1 1}$} \\
\cline { 2 - 4 } & $\mathbf{P}(\boldsymbol{\delta} \mathbf{h \neq 0})(\mathbf{X})$ & $\mathbf{P}(\boldsymbol{\delta} \mathbf{h} \neq \mathbf{0})(\mathbf{Y})$ & $\mathbf{P}(\boldsymbol{\delta} \mathbf{h} \neq \mathbf{0})(\mathbf{Q})$ \\
\hline 1 & 1.000 & 1.000 & 1.000 \\
\hline 2 & 0.010 & 1.000 & 1.000 \\
\hline 3 & 1.000 & 1.000 & 1.000 \\
\hline 4 & 1.000 & 1.000 & 1.000 \\
\hline 5 & 0.010 & 0.010 & 1.000 \\
\hline 6 & 1.000 & 1.000 & 1.000 \\
\hline 7 & 1.000 & 1.000 & 1.000 \\
\hline 8 & & & \\
\hline 9 & 0.773 & 1.000 & 1.000 \\
\hline 10 & 0.496 & 1.000 & 0.623 \\
\hline 11 & 1.000 & 1.000 & 0.817 \\
\hline 12 & 0.995 & 1.000 & 1.000 \\
\hline 13 & 0.143 & 1.000 & 0.829 \\
\hline 14 & 0.995 & 1.000 & 1.000 \\
\hline 15 & & & \\
\hline 16 & & & \\
\hline 17 & 1.000 & 1.000 & 1.000 \\
\hline 18 & 1.000 & 1.000 & 1.000 \\
\hline 19 & 1.000 & 1.000 & 1.000 \\
\hline 20 & & & \\
\hline 21 & & & \\
\hline 22 & & & \\
\hline 23 & & & \\
\hline & & & \\
\hline
\end{tabular}

Table 13. Results of Bayesian analysis with prior data $\mu$

\section{RESULTS AND CONCLUSIONS}

The analysis of the results has been carried out by comparing all surveys with the "zero" defined as the first survey or rather that of the 5/11/2010 and applying the verification tests.

From the results tables there is obvious significant positive altimetric variations or rather subsidence of all the vertices except $10,11,12,13,14$; negative planimetric variations in the direction of the axis $x$ and positive in the direction of the axis $y$ of the vertices $10,11,12,13,14$; planimetric positive variations in the direction of the axis $x$ and negative in $y$-axis direction 9, $17,18,19$. 


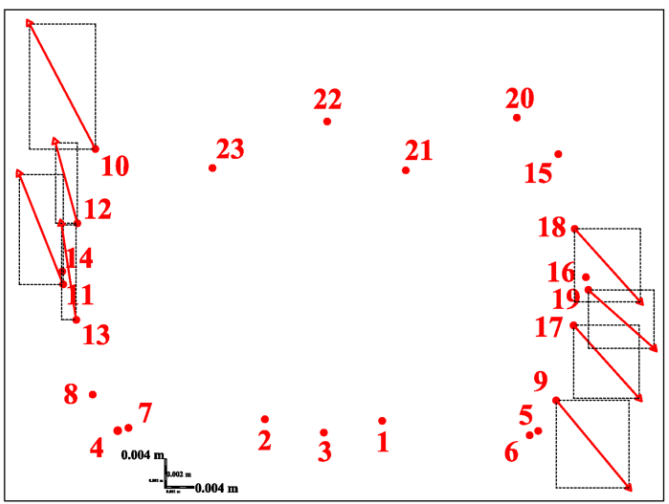

Figure 11. Horizontal displacement vectors

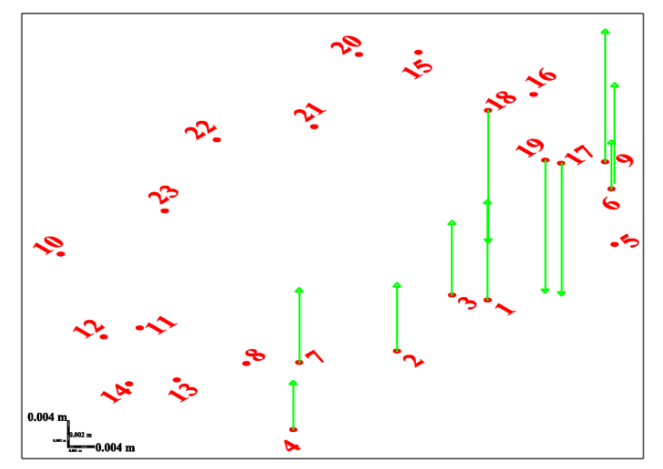

Figure 12. Vertical displacement vectors

The maximum order of these variations can be estimated to the nearest centimeter. For the remaining vertices, no considerations can be formulated given the lower reliability of these measurements.

Analyzing the displacements that each point has had, it would seem that the building undergoes differing movements.

In fact, there is a slipping and lowering of the portion of building attested on the quarry area; and secondly, a different behaviour of the remaining part of a building insistent on the rock. The latter tends to break away from the remaining portion. Even though this hypothesis isn't entirely confirmed by the classic test, it is fully supported by results of Bayesian analysis, especially when the prior data considered are those closest to the phenomena taking place $\left(\mu=0.01 \mathrm{~m}\right.$ and $\left.\sigma_{0}=0.006 \mathrm{~m}\right)$. In light of the monitoring activities carried out in this study, geological and structural technical investigations have been undertaken that have shown the existence of concurrent causes to the movements. In particular, the realization of the Quadrifoglio building on an area which was previously used as a quarry and then filled with debris material characterized by a high degree of permeability has emerged to be the main cause of the dynamics of the movements.

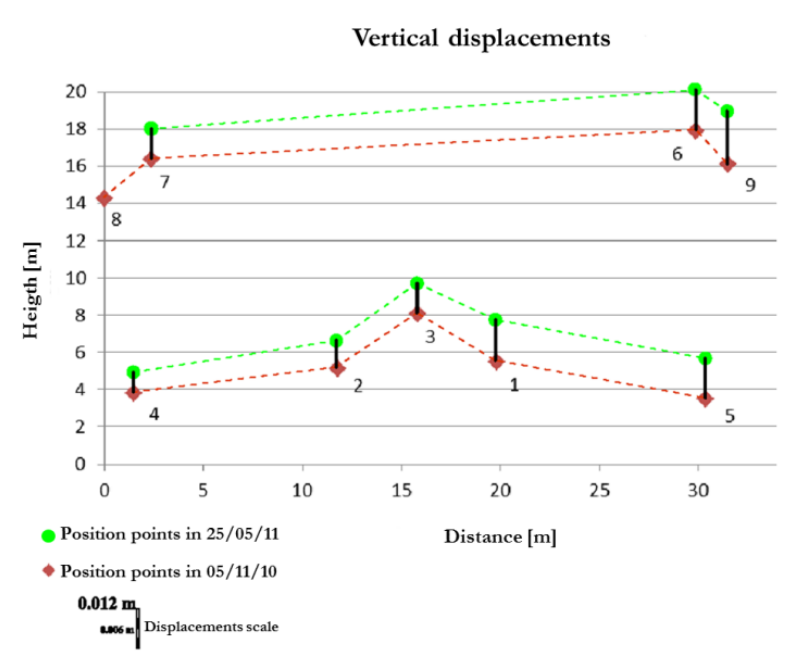

Figure 13. Vertical displacement vectors in West side

\section{REFERENCES}

\section{References from Journals:}

Ball A. D., Cooper J.E., Worden K. (1991), On-line system identification techniques for structural analysis and monitorin", Structural Integrity Assessment, P. Stanley Ed., Elsevier, pp. 236-245

Carpinteri, A., Lacidogna, G., (2006). Structural Monitoring and Integrity Assessment of Medieval Towers. J. Struct. Eng., 132(11), pp.1681-1690.

Costantino, D., Angelini, M. G., (2011). Geodetic monitoring applied to a mine area. Applied Geomatics, 3(2), pp. 61-74.

Deakin, R. E. and Kildea, D. G. (1999), A Note on Standard Deviation and RMS, in The Australian Surveyor, 44 (1), pp. 74-79.

Henriques, M. J., Casaca, J., (2001). Monitoring vertical displacements by means of geometric levelling, Historical Constructions, P. B. Lourenco and P. Roca (eds.), Guimarăes, pp. 403-412.

Sepe, V., Atzori, S., Ventura, G., (2007). Subsidence due to crack closure and depressurization of hydrothermal systems: a case study from Mt Epomeo (Ischia island, Italy). Terra Nova, 19(2), pp.127-132.

Woodhouse, N. G., Robson, S., Eyre, J. R., (1999). Vision metrology and three dimensional visualization in structural testing and monitoring. Photogrammetric Record, 16(94), pp. 625-641.

\section{References from Books:}

Armer, G. S. T., (2001). Monitoring and Assessment of Structures, McGraw Hill, New York.

Baarda, W., (1968). A testing procedure for use in the geodetic network, Neth. Geod. Comm. n. 5. 
Barbarella, M., Radicioni, F., (1990). Kalman Filtering in levelling: an application, Global and Regional Geodynamics, Springer-Verlag, NY.

Beyer, W. H., (1978). CRC Standard Mathematical Tables, 25th Edition.

Cooper, M. A.,R., (1987). Control Surveys in Civil Engineering,William Collins Sons \& Co. Ltd., London.

Glennie, H., Parker-Fell, F., (1997). Monitoring surveying. Presentation to the Joint Engineering Survey Board at the Institution of Civil Engineers, Great George Street, London.

Moore, J.F.A., (1992). Monitoring Building Structures, Blakie\& Son Ltd, Glasgow UK.

Setan, H., (1995). Functional and Stochastic Models for Geometrical Detection of Spatial Deformation in Engineering: A Practical Approach, Ph.D. Thesis, Department of Civil Engineering, City University, London.

\section{References from Other Literature:}

Brebu, F. Bertici, M. R., Bala, A. C., (2012). Using modern topo-geodetic technologies in the process of monitoring building's deformations. 12th International Multidisciplinary Scientific GeoConference, SGEM2012, Vol. 2, pp. 821-828.

Dunisch, M. and Kuhlmann, H. (2001). Investigation on Accuracy of Tracking Motorized Tacheometers, in Optical 3- D Measurement Techniques, A. Grun and H. Kahmen, eds Vienna (Austria), pp. 218-225.

Erol, S., Erol, B., Ayan, T., (2004). A general review of the deformation monitoring techniques and a case study: analysing deformations using GPS/levelling, ISPRS-WG VII/5.

Rothacher, M., Springer, T.A., Schaer, S., Beutler, G., (1997). Processing Strategies for Regional GPS Networks. Proceedings of the IAG General Assembly in Rio, Springer.

Welsch, W., Heunecke, O., (2001). Models and terminology for the analysis of geodetic monitoring observations. FIG 10th International Symposium on Deformation Measurements. International Federation of Surveyors Publication 25. 22 pages.

\section{References from websites:}

http://www.leica-geosystems.it/it/Leica-TS30_77093.htm. 